\title{
Dry Weight Accumulation, Root Plasticity, and Stomatal Conductance in Rice (Oryza sativa L.) Varieties under Drought Stress and Re-Watering Conditions
}

\author{
Doan Cong Dien ${ }^{*}$, Takeo Yamakawa ${ }^{2}$, Toshihiro Mochizuki ${ }^{3}$, Aung Zaw Htwe ${ }^{1}$ \\ ${ }^{1}$ Laboratory of Plant Nutrition, Graduate School of Bioresource and Bioenvironmental Sciences, School of Agriculture, Kyushu \\ University, Fukuoka, Japan \\ ${ }^{2}$ Laboratory of Plant Nutrition, Division of Molecular Biosciences, Department of Biosciences \& Biotechnology, Faculty of \\ Agriculture, Kyushu University, Fukuoka, Japan \\ ${ }^{3}$ Agricultural Ecology Laboratory, Division of Agronomy and Environmental Sciences, Department of Agro-Environmental \\ Sciences, Faculty of Agriculture, Kyushu University, Fukuoka, Japan \\ Email: ${ }^{\star}$ diendoancong@gmail.com
}

How to cite this paper: Dien, D.C., Yamakawa, T., Mochizuki, T. and Htwe, A.Z. (2017) Dry Weight Accumulation, Root Plasticity, and Stomatal Conductance in Rice (Oryza sativa L.) Varieties under Drought Stress and Re-Watering Conditions. American Journal of Plant Sciences, 8, 3189-3206.

https://doi.org/10.4236/ajps.2017.812215

Received: July 14, 2017

Accepted: November 25, 2017

Published: November 28, 2017

Copyright (c) 2017 by authors and Scientific Research Publishing Inc. This work is licensed under the Creative Commons Attribution International License (CC BY 4.0).

http://creativecommons.org/licenses/by/4.0/

\begin{abstract}
Drought is one of the main factors limiting rice (Oryza sativa L.) productivity and has become an increasingly severe problem in many regions worldwide. Establishing breeding programs to develop new drought-tolerant varieties requires an understanding of the effect of drought on rice plants and the mechanisms of drought tolerance in rice. We conducted a pot experiment to explore growth characteristics, root plasticity, and stomatal conductance in six rice varieties (DA8, Malagkit Pirurutong, Thierno Bande, Pate Blanc MN1, Kinandang Patong, and Moroberekan) in response to different drought stress and re-watering conditions. Drought stress significantly depressed plant growth, root size, and stomatal conductance in all experimental varieties. These negative effects depended on both the variety and the severity of the drought stress treatment. Under moderate drought stress (10 days after drought treatment), growth was less influenced in roots than in shoots. In contrast, there was an opposite trend under severe drought stress (15 days after drought treatment), with growth being more severely affected in roots than in shoots. Rice plants recovered from drought stress in terms of dry matter accumulation, root size, and stomatal conductance after re-watering; however, the recovery pattern differed among varieties. DA8 exhibited the highest dry weight accumulation and root size (root length, root surface area, root volume, fine root length, and thick root length) under well-watered, drought stress, and re-watering conditions. Kinandang Patong showed the highest re-
\end{abstract}


covery ability in dry matter accumulation, root length, root surface area, and stomatal conductance after re-watering. Malagkit Pirurutong expressed the poorest recovery ability in dry matter accumulation after re-watering. These three varieties might be selected for further experiments focusing on the mechanisms of drought tolerance and recovery ability in rice.

\section{Keywords}

Drought Tolerance, Recovery Ability, Re-Watering, Rice, Root Morphology

\section{Introduction}

In irrigated lowland rice, water is supplied to satisfy crop requirements during the growth period. Plant water deficit occurs when the crop water demand exceeds supply. Drought is defined as a period when moisture availability is insufficient for maximum or potential growth of crops. In rain-fed ecosystems, drought is the major obstacle to rice production. Developing varieties resistant to drought is considered a promising approach to increase rice yields in drought-prone environments. However, this approach requires an understanding of rice plant responses to drought and the mechanisms of drought tolerance in rice.

A number of comprehensive reviews of drought response in rice have been published [1] [2] [3] [4]. Rice adapts to drought stress through the induction of various morphological, physiological, and biochemical responses. Drought responses may be highly variable depending on the severity, duration, and timing of drought stress as well as the characteristics of different varieties [5].

The growth and development of leaves, stems, and roots can be severely affected by water stress. Drought stress leads to decreased numbers of leaves, reduced leaf elongation, leaf rolling, discoloration in green leaves, and the promotion of leaf death [6] [7] [8]. Leaf stomata are particularly sensitive to drought stress. Leaf stomatal conductance decreases sharply with decreases in leaf water potential [9], reducing photosynthesis and radiation-use efficiency rates. Drought severely affects plant growth and development, with substantial reductions in crop growth rate and biomass accumulation [10]. These responses reduce dry matter production and eventually grain yield.

Rice is a shallow-root crop susceptible to drought. Because plants acquire water from the soil, root growth, density, proliferation, and size are key factors in drought stress resistance [11]. The ability of plants to change their root morphology [12] and physiological functions [13] in response to fluctuations in environmental conditions, known as root plasticity, may play an important role in plant adaptation to various intensities of drought stress in rice [14]. O'Toole and Chang [15] found that rice varieties with longer and thicker roots were more drought-resistant than those with shorter and thinner roots. In another study, 
rice varieties with deeper root systems were found to be better adapted to drier conditions [16].

The ability of a plant to recover following drought stress is also considered an important trait determining rice grain yield [17] [18]. Some researchers have suggested that drought recovery ability is more important than drought tolerance [19]. The ability to recover from desiccation during vegetative growth is an important factor affecting the productive capacity of rice [20].

The objective of the present study was to analyze the responses of different rice varieties in terms of dry weight accumulation, root morphology, and stomatal conductance under different drought stress and re-watering conditions.

\section{Materials and Methods}

\subsection{Materials and Experimental Design}

From the previous screening at seedling stage using 172 rice varieties [21], we selected two drought-tolerant varieties (DA8 and TheirnoBande) and two drought-sensitive varieties (Malagkit Pirurutong and Blanc MN1) for this experiment. In addition, two other varieties (Kinandang Patong and Moroberekan) were used as the check varieties in this experiment. We assigned various codes to six rice varieties from different ecological regions including DA8 (Bangladesh: V1), Malagkit Pirurutong (Philippines: V2), Thierno Bande (Senegal: V3), Pate Blanc MN1 (Ivory Coast: V4), Kinandang Patong (Philippines: V5), and Moroberekan (Guinea: V6). We then performed a pot experiment in a greenhouse at the Faculty of Agriculture, Kyushu University, Japan $\left(33^{\circ} 37^{\prime} \mathrm{N}, 130^{\circ} 25^{\prime} \mathrm{E} ; 3 \mathrm{~m}\right.$ above sea level) in summer 2015. The experiment was conducted in a randomized complete block design with three replicates.

The air temperature and humidity within the greenhouse were measured using a TR-72wf Thermo Recorder (T \& D Corporation, Matsumo, Japan). Soil temperatures during the control and drought trials were recorded using a TR-71U Thermo Recorder (T \& D Corporation). Soil moisture content was measured with a EC 5 soil moisture sensor (Decagon, Pullman, WA, USA); these data were calibrated and converted to soil moisture content (\% water weight/fresh soil weight).

For this experiment, we used Futsukaichi soil (sandy loam), which was originally komatsuna-cultivated soil but was sampled and stored for a long period in the laboratory. The water-holding capacity of the soil was $47.8 \%$. We prepared the soil by adding $3.0 \mathrm{~kg}$ of air-dried Futsukaichi soil (13\% moisture content) to each 1/5000 Wagner pot. To each pot, we applied fertilizer as follows: $0.2 \mathrm{~g} \mathrm{~N}+$ $0.2 \mathrm{~g} \mathrm{P}_{2} \mathrm{O}_{5}+0.2 \mathrm{~g} \mathrm{~K}_{2} \mathrm{O}$. Fertilizer was applied 2 days before the sowing day.

\subsection{Drought Treatments}

Drought treatments were started 4 weeks after sowing by withdrawing the water from drought treatment pots while retaining a water level of $1-2 \mathrm{~cm}$ above the soil surface in control pots (well-watered). The drought treatments were divided 
into two levels: moderate drought and severe drought, with drought periods of 10 and 15 days, respectively. After the drought treatment, plants were re-watered to permit recovery.

\subsection{Sampling and Measurement}

Stomatal conductance (gs) was measured from 10:00 to 13:00 every 5 days during the drought treatment stage and 3 days after re-watering at the second from the top expanded leaves using a leaf porometer (Decagon). In this experiment, there were five sampling times including: 1:1 day before drought treatment; 2:10 days after drought treatment (moderate drought); 3:15 days after drought treatment (severe drought); 4:7 days after re-watering following moderate drought; and 5:7 days after re-watering following severe drought.

For each sampling time, we collected one plant from each variety in each replicate. Leaves and stems were detached, dried at $70^{\circ} \mathrm{C}$ for 48 hours, and then analyzed for leaf dry weight and stem dry weight. Root morphological traits (total length, surface area, volume, and diameter) were analyzed using the Win RHIZO system (Regent Instruments, Quebec City, Canada), which interacts with the image scanner. The roots were grouped into diameter classes (fine roots: diameter $\leq 0.3 \mathrm{~mm}$, thick roots: diameter $>0.3 \mathrm{~mm}$ ) following a method used in previous studies [22] [23]. After morphological analysis, root samples were dried at $70^{\circ} \mathrm{C}$ for 48 hours and then root dry weight was measured.

\subsection{Statistical Analysis}

Analysis of variance was used to test for differences, and Tukey's test was used to determine significant differences at the $5 \%$ probability level using STAR software (IRRI, 2013).

\section{Results}

\subsection{Climate Data and Soil Moisture Content}

During the experimental period, air temperature and soil temperature in all treatments remained stable, from $25^{\circ} \mathrm{C}$ to $30^{\circ} \mathrm{C}$; relative humidity fluctuated from $60 \%$ to greater than $80 \%$ (Figure 1). At later stages of the experiment, the soil temperature in the drought trial was slightly higher than that in the control trial.

Soil moisture content (\%) decreased dramatically following drought treatment. At 1 day after drought treatment, soil moisture had decreased to $28 \%$. A sudden decrease in soil moisture content occurred from 2 to 5 days after drought treatment and then soil moisture gradually decreased until the end of the drought treatment. The soil moisture content of varieties V1, V2, and V3 decreased more rapidly than that of V6, V4, and V5 (Figure 1). The soil moisture content fell to approximately $15 \%$ at 10 days after drought treatment (moderate drought) and $13 \%$ at 15 days after drought treatment (severe drought). 

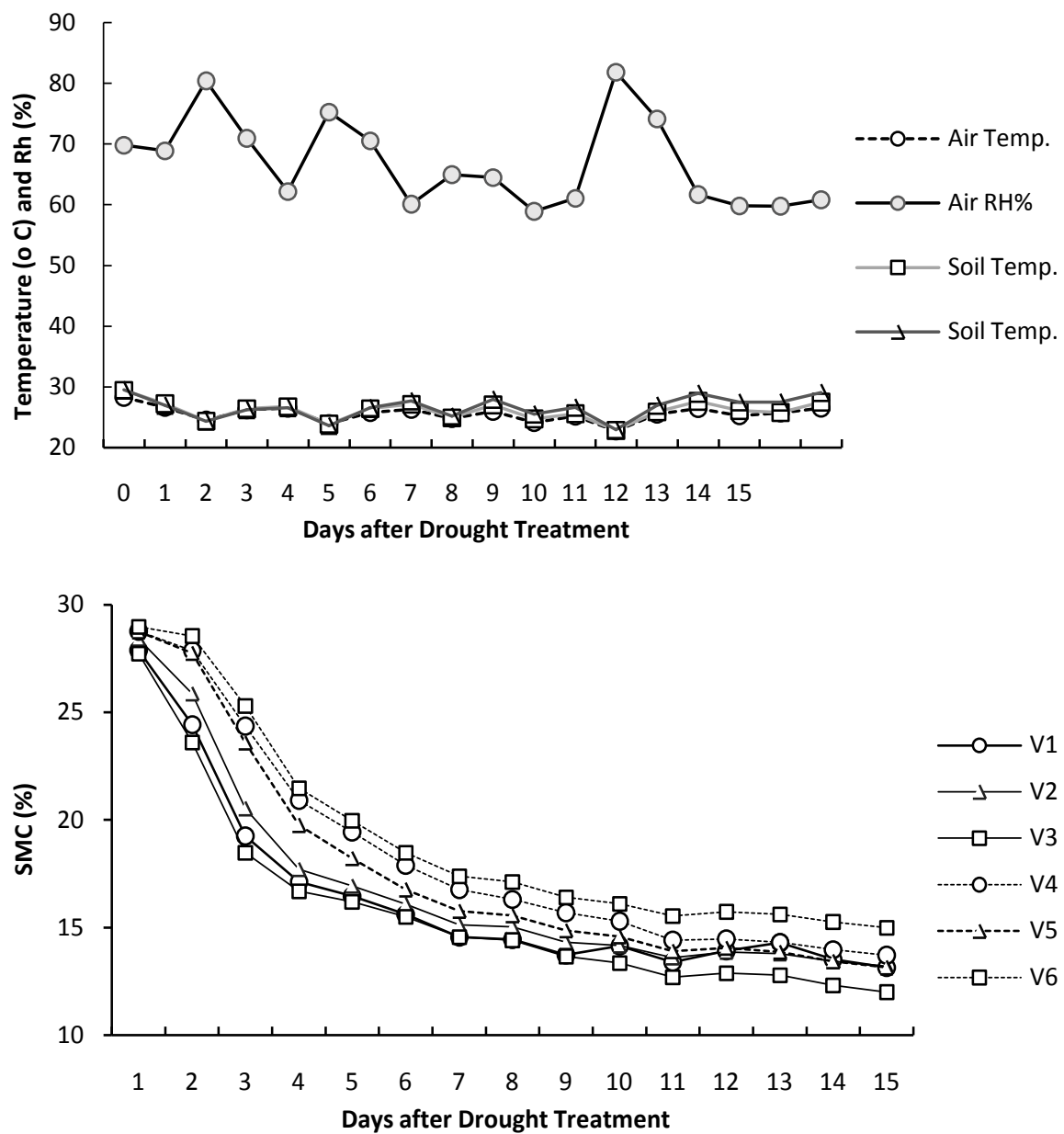

Figure 1. Environmental characteristics and soil moisture content for each variety through experimental time. SMC: Soil Moisture Content (\% water weight/fresh soil weight).

\subsection{Leaf Dry Weight Accumulation}

Leaf dry weight (LDW) data for the experimental varieties under well-watered, drought stress, and re-watering conditions are presented in Table 1. Before the drought treatment, there was no significant difference in LDW between experimental varieties, although the absolute values of V1 and V3 were higher than those of other varieties. At later stages of the experiment, however, a significant difference between varieties in LDW accumulation was observed under both control (well-watered) and drought conditions. Under well-watered conditions, V1, V2, and V3 generally retained a higher LDW than did other genotypes.

Drought stress significantly decreased the LDW of all varieties in comparison with control conditions throughout the experimental period. However, this pattern of decrease occurred at different rates between varieties. At moderate drought stress, V1 accumulated more LDW (2.12 g.plant $\left.{ }^{-1}\right)$ than other varieties, significantly higher than that of V2 (1.31 g.plant $\left.{ }^{-1}\right)$, which exhibited the lowest LDW among the varieties. Under severe drought stress, V1 and V3 demonstrated the greatest ability to accumulate LDW, at $2.32 \mathrm{~g} \cdot$ plant $^{-1}$ and $2.18 \mathrm{~g} \cdot \mathrm{plant}^{-1}$, 
respectively. Under severe drought stress, V4 accumulated the lowest LDW (only $1.45 \mathrm{~g} \mathrm{LDW}_{\text {plant }}{ }^{-1}$ ) in comparison with other varieties. During the recovery period, there were no significant differences in LDW for either moderate drought or severe drought conditions.

\subsection{Stem Dry Weight Accumulation}

Table 2 shows the stem dry weight (SDW) data for experimental varieties in different conditions. Before drought treatment, the SDW of V4 (0.95 g.plant $\left.{ }^{-1}\right)$ was lower than that of all other varieties. Differences in SDW between varieties

Table 1. Leaf dry weight $\left(\mathrm{g} \cdot\right.$ plant $\left.^{-1}\right)$ of varieties under different conditions.

\begin{tabular}{|c|c|c|c|c|c|c|c|}
\hline \multirow{2}{*}{\multicolumn{2}{|c|}{ Treatments }} & \multicolumn{6}{|c|}{ Varieties } \\
\hline & & V1 & V2 & V3 & V4 & V5 & V6 \\
\hline $\mathrm{BDT}$ & & $1.95_{\mathrm{a}}$ & $1.28_{\mathrm{a}}$ & $1.95_{\mathrm{a}}$ & $1.18_{\mathrm{a}}$ & $1.39_{\mathrm{a}}$ & $1.24_{\mathrm{a}}$ \\
\hline \multirow{2}{*}{$\mathrm{MD}$} & Control & $3.75^{*}$ & $3.02^{*}{ }_{a b}$ & $3.12_{\mathrm{ab}}^{*}$ & $2.25^{*} \mathrm{c}$ & $2.65_{\mathrm{bc}}^{*}$ & $2.81_{\mathrm{bc}}^{*}$ \\
\hline & Drought & $2.12_{\mathrm{a}}$ & $1.31_{\mathrm{b}}$ & $1.86_{\mathrm{ab}}$ & $1.64_{\mathrm{ab}}$ & $1.72_{\mathrm{ab}}$ & $1.84_{\mathrm{ab}}$ \\
\hline \multirow{2}{*}{ SD } & Control & $4.31_{\mathrm{a}}^{*}$ & $3.70^{*} \mathrm{~b}$ & $3.38_{\mathrm{bc}}^{*}$ & $2.79_{\mathrm{d}}^{*}$ & $3.05^{*} \mathrm{~cd}$ & $2.94_{\mathrm{cd}}^{*}$ \\
\hline & Drought & $2.32_{\mathrm{a}}$ & $1.76_{\mathrm{bc}}$ & $2.18_{\mathrm{ab}}$ & $1.45_{c}$ & $1.65_{\mathrm{bc}}$ & $1.84_{\mathrm{abc}}$ \\
\hline \multirow{2}{*}{ RMD } & Control & $3.81_{\mathrm{a}}^{*}$ & $3.43^{*}{ }_{\mathrm{ab}}$ & $3.33^{*}{ }_{a b c}$ & $2.67^{*}$ & $2.89^{*} \mathrm{bc}$ & $2.94_{\mathrm{bc}}^{*}$ \\
\hline & Recovery & $1.64 \mathrm{a}$ & $1.04 \mathrm{a}$ & $1.45_{\mathrm{a}}$ & $1.32_{\mathrm{a}}$ & $1.55_{\mathrm{a}}$ & $1.46_{\mathrm{a}}$ \\
\hline \multirow{2}{*}{ RSD } & Control & $3.97^{*}$ & $3.88_{\mathrm{ab}}^{*}$ & $3.88_{\mathrm{ab}}^{*}$ & $2.87^{*}{ }_{c}$ & $3.27^{*}{ }_{b c}$ & $3.33^{*}{ }_{\mathrm{abc}}$ \\
\hline & Recovery & $0.29 \mathrm{a}$ & $0.39_{\mathrm{a}}$ & $0.53_{\mathrm{a}}$ & $0.55_{\mathrm{a}}$ & $0.61_{\mathrm{a}}$ & $0.42_{\mathrm{a}}$ \\
\hline
\end{tabular}

BDT: Before Drought Treatment; MD: Moderate Drought; SD: Severe Drought; RMD: Recovery from Moderate Drought; RSD: Recovery from Severe Drought; "Significant difference between control and drought conditions in the same variety at $\mathrm{p}<0.05$; Means with the same letter are not significant difference between varieties under the same condition at $\mathrm{p}<0.05$ by Tukeys's HSD Test $(n=3)$.

Table 2. Stem dry weight (g.plant ${ }^{-1}$ ) of varieties under different conditions.

\begin{tabular}{|c|c|c|c|c|c|c|c|}
\hline \multirow{2}{*}{\multicolumn{2}{|c|}{ Treatments }} & \multicolumn{6}{|c|}{ Varieties } \\
\hline & & V1 & $\mathrm{V} 2$ & V3 & V4 & V5 & V6 \\
\hline BDT & & $1.68_{\mathrm{a}}$ & $1.30_{\mathrm{ab}}$ & $1.64_{\mathrm{a}}$ & $0.95_{\mathrm{b}}$ & $1.27_{\mathrm{ab}}$ & $1.09_{\mathrm{ab}}$ \\
\hline \multirow{2}{*}{$\mathrm{MD}$} & Control & $4.79_{\mathrm{a}}^{*}$ & $3.82^{*}$ & $4.17_{\mathrm{ab}}^{*}$ & $2.53^{*}{ }_{c}$ & $3.45_{\mathrm{b}}^{*}$ & $3.42^{*}$ \\
\hline & Drought & $2.71_{\mathrm{a}}$ & $2.34_{\mathrm{ab}}$ & $2.52_{\mathrm{ab}}$ & $1.77_{\mathrm{b}}$ & $2.01_{\mathrm{ab}}$ & $1.98_{\mathrm{ab}}$ \\
\hline \multirow{2}{*}{ SD } & Control & $8.90^{*}$ & $6.29_{\mathrm{b}}^{*}$ & $5.62^{*}{ }_{b c}$ & $4.33^{*}{ }_{c}$ & $5.17^{*} \mathrm{bc}$ & $5.17^{*} \mathrm{bc}$ \\
\hline & Drought & $2.42^{\mathrm{a}}$ & $1.82^{\mathrm{ab}}$ & $2.40^{\mathrm{a}}$ & $1.43^{\mathrm{b}}$ & $1.67^{\mathrm{b}}$ & $1.73^{\mathrm{b}}$ \\
\hline \multirow{2}{*}{ RMD } & Control & $7.55_{\mathrm{a}}^{*}$ & $5.84_{\mathrm{b}}^{*}$ & $6.49_{\mathrm{b}}^{*}$ & $3.78^{*}{ }_{d}$ & $4.53^{*}{ }_{\mathrm{cd}}$ & $4.80^{*} \mathrm{c}$ \\
\hline & Recovery & $2.85_{\mathrm{a}}$ & $2.22_{\mathrm{bc}}$ & $2.89_{\mathrm{a}}$ & $2.01_{c}$ & $2.59_{\mathrm{ab}}$ & $2.42_{\mathrm{bc}}$ \\
\hline \multirow{2}{*}{ RSD } & Control & $9.81^{*}{ }_{a}$ & $7.27^{*} \mathrm{bc}$ & $7.66_{\mathrm{b}}^{*}$ & $4.47_{\mathrm{d}}^{*}$ & $5.98_{\mathrm{cd}}^{*}$ & $5.93^{*}{ }_{\mathrm{cd}}$ \\
\hline & Recovery & $2.07_{\mathrm{a}}$ & $1.85_{\mathrm{ab}}$ & $1.87_{\mathrm{ab}}$ & $1.42_{\mathrm{b}}$ & $1.70_{\mathrm{ab}}$ & $1.64_{\mathrm{ab}}$ \\
\hline
\end{tabular}

Foot notes: Same to Table 1. 
under well-watered conditions were observed throughout the later stages of the experiment, where V1 always accumulated the highest SDW under well-watered conditions and V4 the lowest.

Similar to the pattern observed in LDW (Table 1), SDW was decreased significantly under drought stress compared with that under control conditions. At moderate drought stress, V4 showed the lowest SDW value (1.77 g.plant $\left.{ }^{-1}\right)$; there was no significant difference in SDW among other experimental varieties, despite the fact that V1 retained the highest absolute value at 2.71 g.plant ${ }^{-1}$. Interestingly, there were no significant differences in SDW between varieties under severe drought treatment, despite higher absolute values in V1 and V3. After 7 days of re-watering following moderate drought, V2 and V4 accumulated lower amounts of SDW than did other varieties. The SDW values for these varieties were only $2.22 \mathrm{~g}$.plant ${ }^{-1}$ and $2.01 \mathrm{~g} \cdot$ plant $^{-1}$, respectively. After 7 days of re-watering following severe drought, there was no significant difference in SDW accumulation between varieties, although $\mathrm{V} 1$ had the highest absolute value, at 2.07 g.plant ${ }^{-1}$.

\subsection{Root Dry Weight Accumulation}

Before drought treatment, the root dry weight (RDW) values of V3 (0.50 g.plant $\left.{ }^{-1}\right)$ and V1 (0.40 g.plant $\left.{ }^{-1}\right)$ were significantly higher than those of other varieties (Table 3). Similarly, under control conditions in later stages of the experiment, V1 and V3 consistently accumulated higher RDW than did other experimental varieties. However, in the last sampling, there was no significant difference in RDW between varieties under control conditions.

Moderate drought stress significantly depressed RDW accumulation in V1, $\mathrm{V} 2$, and V3, but not in V4, V5, and V6 in comparison to control conditions. However, during the stage of recovery from moderate drought stress, the RDW

Table 3. Root dry weight (g.plant ${ }^{-1}$ ) of varieties under different conditions.

\begin{tabular}{|c|c|c|c|c|c|c|c|}
\hline \multirow{2}{*}{\multicolumn{2}{|c|}{ Treatments }} & \multicolumn{6}{|c|}{ Varieties } \\
\hline & & V1 & $\mathrm{V} 2$ & V3 & V4 & V5 & V6 \\
\hline $\mathrm{BDT}$ & & $0.40_{\mathrm{ab}}$ & $0.21_{\mathrm{b}}$ & $0.50_{\mathrm{a}}$ & $0.13_{\mathrm{b}}$ & $0.21_{\mathrm{b}}$ & $0.16_{\mathrm{b}}$ \\
\hline \multirow{2}{*}{$\mathrm{MD}$} & Control & $2.64_{\mathrm{a}}^{*}$ & $1.77_{\mathrm{cd}}^{*}$ & $2.33_{\mathrm{ab}}^{*}$ & $1.27_{\mathrm{d}}$ & $1.77_{\mathrm{cd}}^{*}$ & $1.84_{\mathrm{bc}}$ \\
\hline & Drought & $1.74_{\mathrm{a}}$ & $1.38_{\mathrm{a}}$ & $1.68_{\mathrm{a}}$ & $1.28_{\mathrm{a}}$ & $1.43_{\mathrm{a}}$ & $1.63_{\mathrm{a}}$ \\
\hline \multirow{2}{*}{$\mathrm{SD}$} & Control & $4.66_{\mathrm{a}}^{*}$ & $3.95_{\mathrm{ab}}^{*}$ & $3.83_{\mathrm{ab}}^{*}$ & $3.08_{\mathrm{b}}^{*}$ & $3.31_{\mathrm{b}}^{*}$ & $3.51_{\mathrm{b}}^{*}$ \\
\hline & Drought & $1.30_{\mathrm{a}}$ & $1.37 \mathrm{a}$ & $1.25_{\mathrm{a}}$ & $1.24 \mathrm{a}$ & $1.32_{\mathrm{a}}$ & $1.40_{\mathrm{a}}$ \\
\hline \multirow{2}{*}{ RMD } & Control & $4.10_{\mathrm{ab}}^{*}$ & $3.63_{\mathrm{bc}}^{*}$ & $4.52^{*}{ }_{\mathrm{a}}$ & $3.34_{c}^{*}$ & $3.13^{*}{ }_{c}$ & $3.96_{\mathrm{b}}^{*}$ \\
\hline & Recovery & $2.33_{\mathrm{a}}$ & $1.68_{\mathrm{b}}$ & $2.15_{\mathrm{ab}}$ & $1.71_{\mathrm{b}}$ & $2.07_{\mathrm{ab}}$ & $2.10_{\mathrm{ab}}$ \\
\hline \multirow{2}{*}{ RSD } & Control & $5.60^{*}{ }_{a}$ & $4.74_{\mathrm{a}}^{*}$ & $5.32^{*}{ }_{\mathrm{a}}$ & $4.32^{*}{ }_{\mathrm{a}}$ & $4.02^{*}{ }_{\mathrm{a}}$ & $5.14_{\mathrm{a}}^{*}$ \\
\hline & Recovery & $1.43_{\mathrm{a}}$ & $1.22_{\mathrm{a}}$ & $1.42_{\mathrm{a}}$ & $1.03_{\mathrm{a}}$ & $1.15_{\mathrm{a}}$ & $1.41_{\mathrm{a}}$ \\
\hline
\end{tabular}

Foot notes: Same to Table 1. 
values of all varieties in the drought treatment group were significantly lower than those in the control group. The RDW values of V2 (1.68 g.plant $\left.{ }^{-1}\right)$ and V4 $\left(1.70\right.$ g.plant $\left.{ }^{-1}\right)$ at 7 days of re-watering following moderate drought were lower than those of other varieties. The RDW values of all varieties under severe drought stress were significantly reduced compared with those under control conditions, and this pattern continued after re-watering.

\subsection{Drought/Control Ratios for Dry Weight Accumulation}

Under moderate drought stress, the RDW drought/control ratio of experimental varieties was higher than those for LDW and SDW. In contrast, under severe drought stress, the LDW and SDW drought/control ratios were higher than the RDW ratios (Figure 2).

Under moderate drought stress, the total dry weight (TDW) drought/control ratio in V4 was higher than those of other varieties. LDW was more severely affected in V2 under moderate and severe drought stress than in other varieties. At 7 days of re-watering following moderate drought, V5 expressed the highest dry
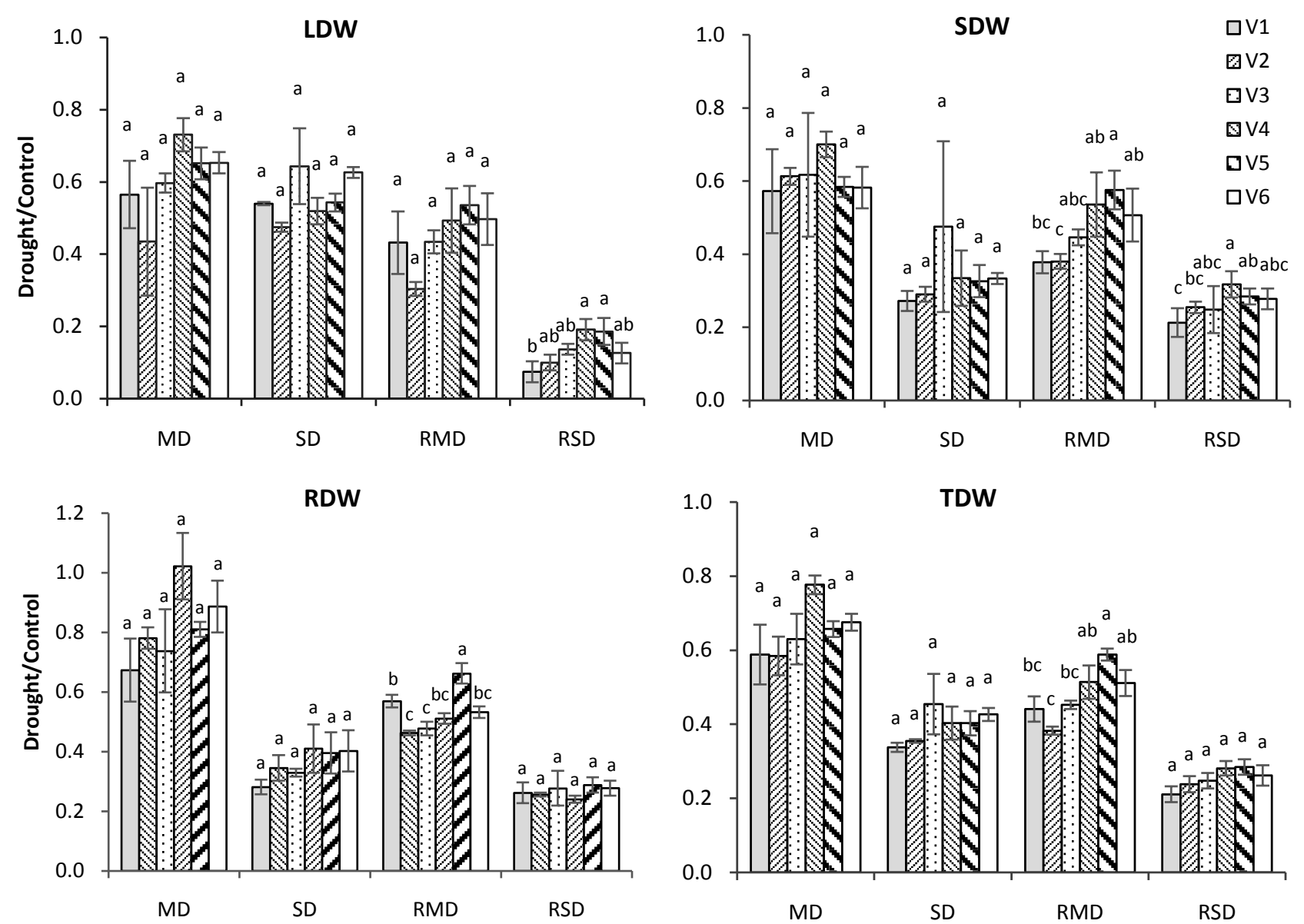

Figure 2. Drought/control ratios for Leaf Dry Weight (LDW), Stem Dry Weight (SDW); Root Dry Weight (RDW) and Total Dry Weight (TDW) of varieties under different conditions. MD: Moderate Drought; SD: Severe Drought; RMD: Recovery from Moderate Drought; RSD: Recovery from Severe Drought; Means with the same letter are not significant difference between varieties under the same condition at $\mathrm{p}<0.05$ by Tukeys's HSD Test $(n=3)$. 
weight accumulation (in leaves, stems, and roots) recovery/control ratios among the varieties, whereas V2 exhibited the lowest ratios. At 7 days of re-watering following severe drought, the dry weight recovery/control ratios of all varieties were only approximately 0.2 , and there were no significant differences between varieties.

\subsection{Root Morphology under Well-Watered, Drought, and Re-Watering Conditions}

Root morphological characteristics such as total root length (RL), root surface area (RSA), root volume (RV), root diameter (RD), fine root length (FRL), and thick root length (TRL) are shown in Figures 3-7.

Before drought treatment, there were no significant differences in RL between varieties. In later stages, under well-watered conditions, V1 and V3 expressed higher RL values than other varieties (Figure 3 ). RL values were significantly lower in drought stress treatments than in control treatments. Interestingly, under moderate drought and severe drought stress, there were no significant differences in RL between varieties. However, a significant difference in RL between varieties was observed after re-watering. During the recovery stage following moderate drought, the RL values of V1, V3, and V5 were higher than those of other varieties, whereas V2 expressed the lowest RL value. Similarly, the V2 RL value was lower than those of other varieties during recovery from severe drought.

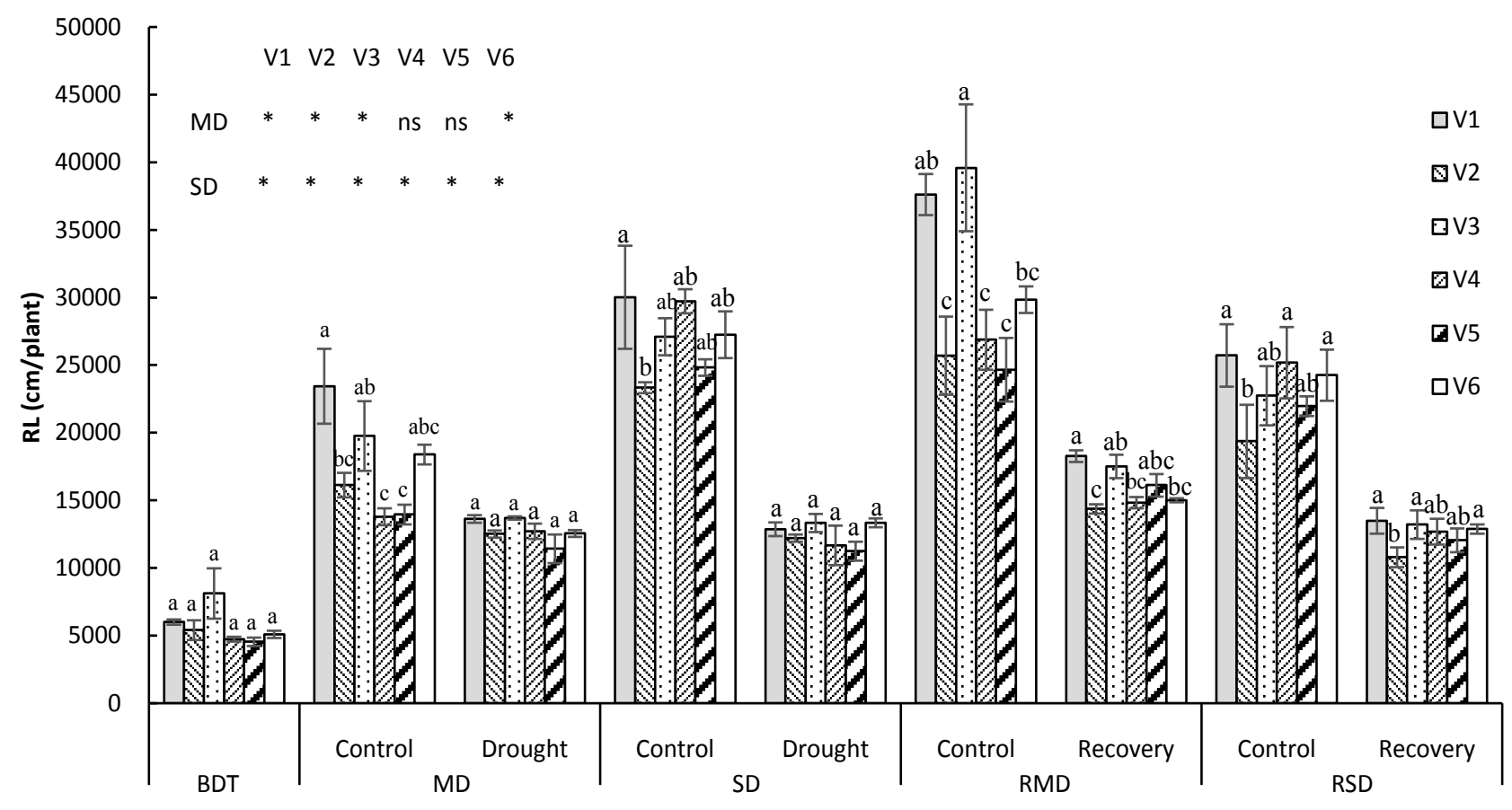

Figure 3. Total root length of varieties under different conditions. BDT: Before Drought Treatment; MD: Moderate Drought; SD: Severe Drought; RMD: Recovery from Moderate Drought; RSD: Recovery from Severe Drought. *Significant difference between control and drought conditions at $\mathrm{p}<0.05$; Means with the same letter are not significant difference between varieties under the same condition at $\mathrm{p}<0.05$ by Tukeys's HSD Test $(n=3)$. 


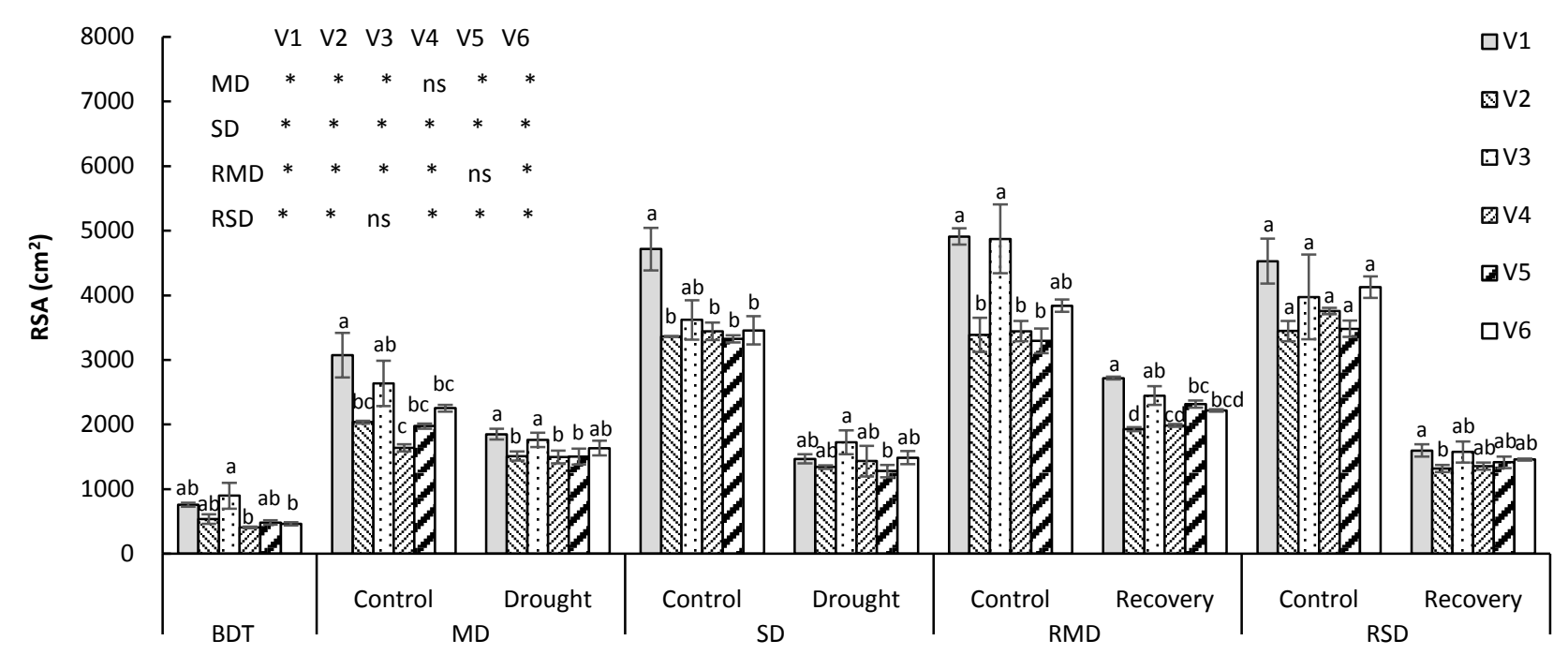

Figure 4. Root surface area (RSA) of varieties under different conditions. Foot notes: Same to Figure 3.

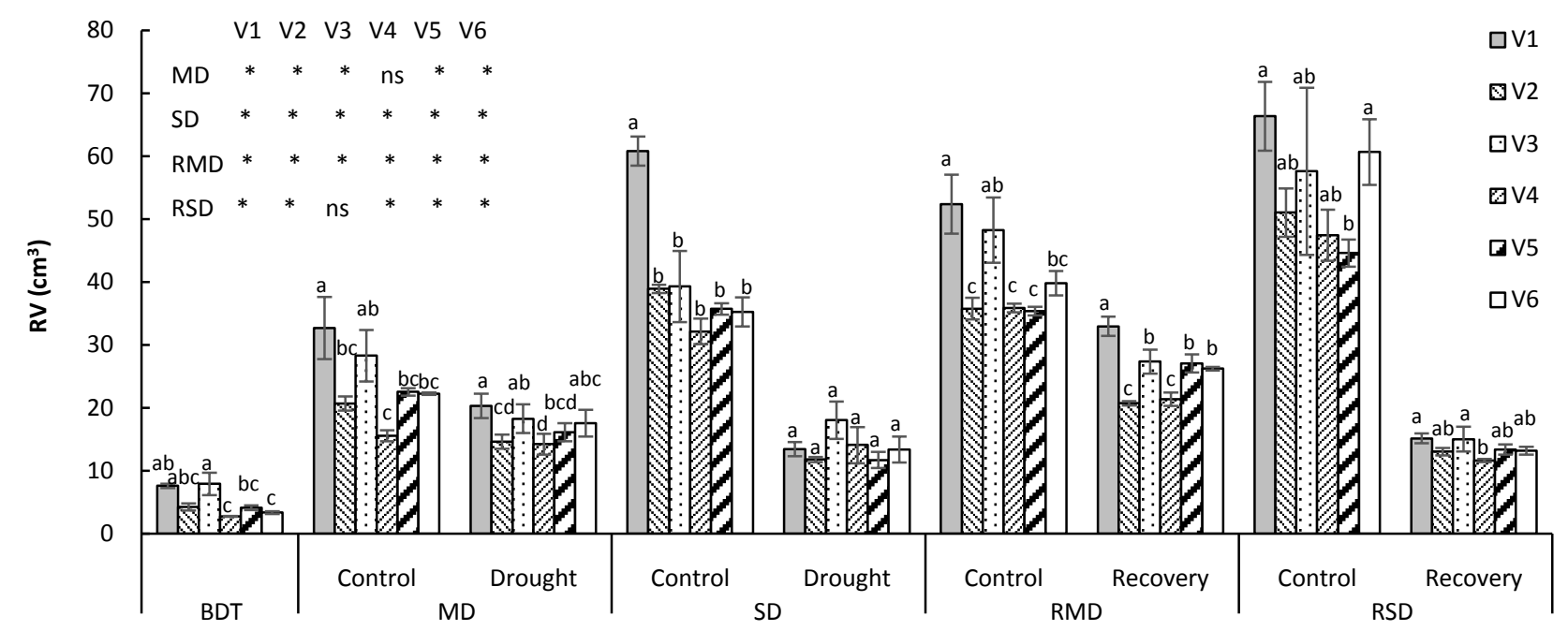

Figure 5. Root volume (RV) of varieties under different conditions. Foot notes: Same to Figure 3.

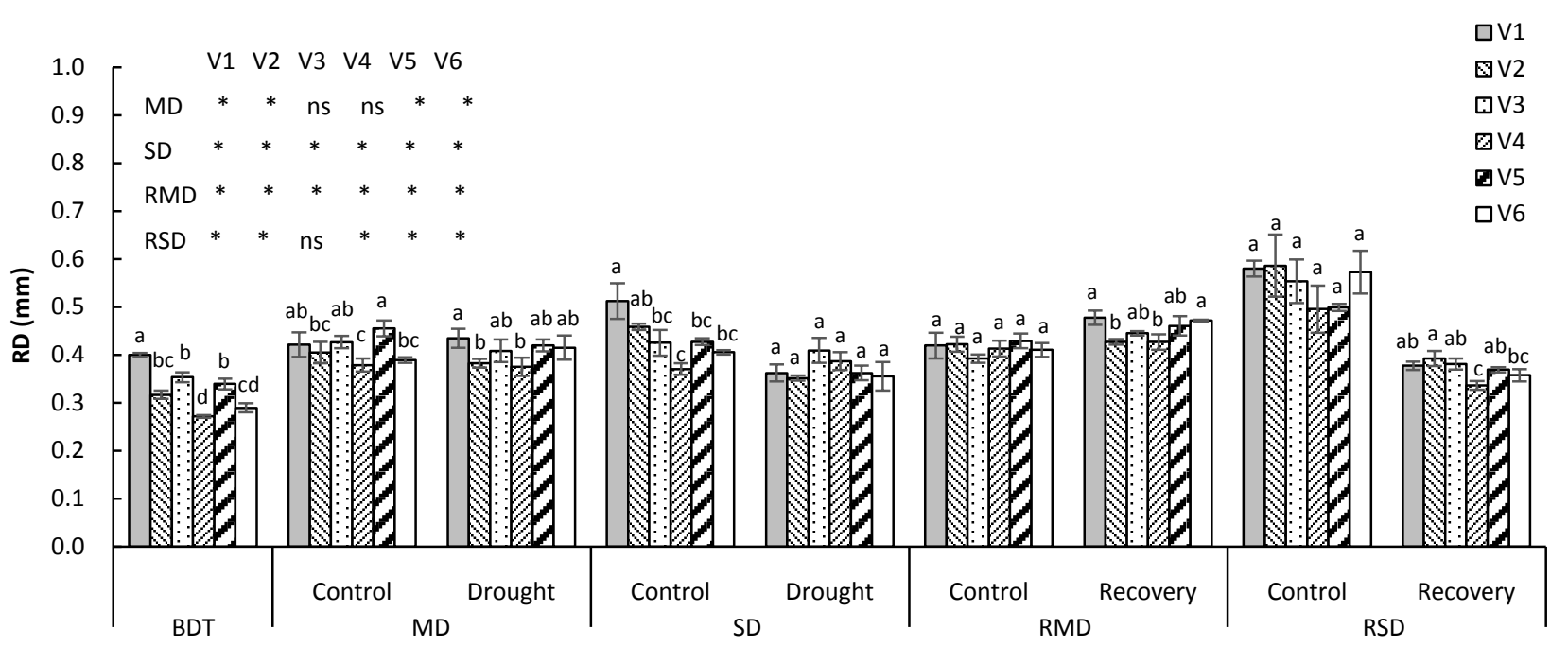

Figure 6. Root diameter (mm) of varieties under different conditions. Foot notes: Same to Figure 3. 
Under control conditions, V1 and V3 RSA values were generally higher than those of other varieties during the study period. Similar to the trend observed in RL, RSA values were significantly depressed under drought stress compared with those under well-watered conditions (Figure 4). Under moderate drought stress, the RSA values of V1, V3, and V6 were higher than those of V2, V4, and V5. Under severe drought stress, V5 showed the lowest RSA value among all varieties. During recovery following moderate and severe drought stress, the RSA value of V4 was lower than those of other varieties (Figure 4).

$\mathrm{RV}$ values under different treatments are illustrated in Figure 5. Under control conditions, V1 always presented higher RV values than the other varieties did. Moderate and severe drought stress significantly decreased RV values in comparison with those under control conditions. Under moderate drought stress, V2 and V4 had the lowest RV among varieties. Under severe drought stress, there were no significant differences in RV between varieties. The RV values recovered after re-watering following moderate drought stress. At 7 days of re-watering following moderate drought, the RV value of V1 was highest (32.96 $\mathrm{cm}^{3} /$ plant), and V2 and V4 exhibited the lowest RV values (20.73 $\mathrm{cm}^{3} /$ plant and $21.37 \mathrm{~cm}^{3} /$ plant, respectively) compared to other varieties.

Before drought treatment, the $\mathrm{RD}$ value of $\mathrm{V} 1$ was higher than those of other varieties (Figure 6). Moderate drought stress led to decreased $\mathrm{RD}$ values in $\mathrm{V} 2$ and V5, but increased RD values in V6 and no significant differences among other varieties. Severe drought stress significantly decreased RD values in V1, V2, and V5 compared to those under control conditions. Under moderate drought stress, the RD of V1 was highest, and V2 and V4 showed lower RD values than all other varieties. However, there were no significant differences in $\mathrm{RD}$ between varieties under severe drought stress. At 7 days of re-watering following moderate drought, the $\mathrm{RD}$ values of $\mathrm{V} 1, \mathrm{~V} 3$, and V6 were significantly higher than those under control conditions. In contrast, the RD values of $\mathrm{V} 1, \mathrm{~V} 3, \mathrm{~V} 5$, and V6 at 7 days of re-watering following severe drought remained significantly lower than those in control conditions (Figure 6).

FRL values for different treatments are presented in Figure 7(a). There were no significant differences in FRL among varieties before drought treatment. In the later stages of the experiment, V1 and V3 generally showed higher FRL values under well-watered conditions than did other varieties. Moderate drought stress significantly decreased FRL in all varieties except V4 and V5. Under severe drought stress, the FRL values of all varieties significantly decreased compared to those under well-watered conditions. There were no significant differences in FRL among varieties under moderate and severe drought stress. During recovery from moderate drought, FRL values were lower in V2 and V6 than in other varieties. Similarly, the FRL of V2 during recovery from severe drought was lowest among all varieties (Figure $7(a)$ ).

The TRL values of V1 and V3 under control conditions were consistently higher than those of other varieties during the study period (Figure $7(b)$ ). 

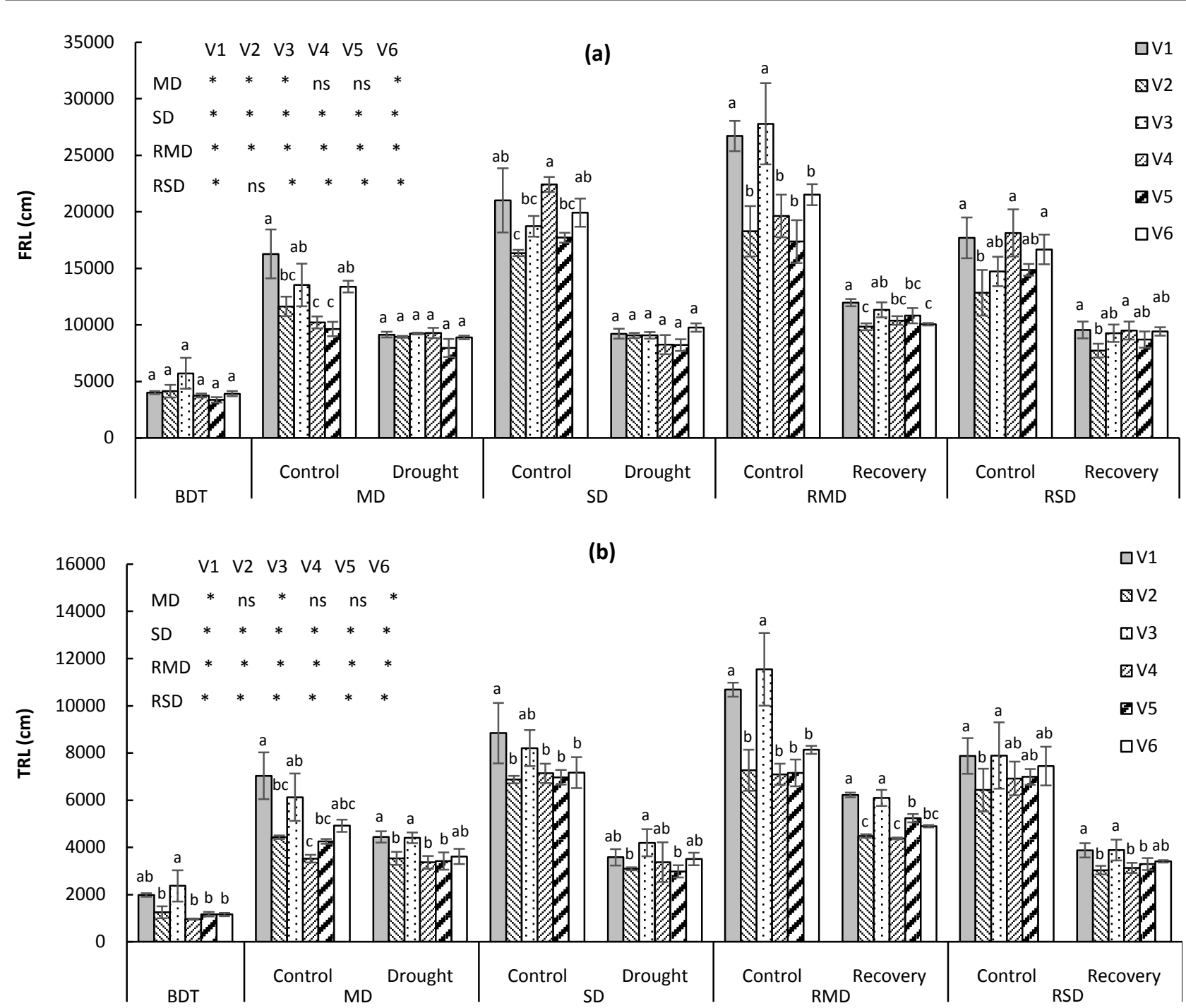

Figure 7. (a), (b). Fine Root Length (FRL) and Thick Root Length (TRL) of varieties under different conditions. Foot notes: Same to Figure 3.

Moderate drought stress significantly decreased TRL values in V1, V3, and V6, but not in other varieties. However, severe drought stress significantly reduced the TRL of all varieties in drought treatments compared to those under control conditions. There were no significant differences in TRL among varieties under moderate and severe drought stress. During recovery from moderate and severe drought stress, however, V2 exhibited the lowest TRL values compared to those of other varieties (Figure 7(b)).

Figure 8 shows the drought/control ratios for root morphology measurements of the varieties under different conditions. The development of the root system was depressed under drought stress, and this negative effect was stronger under severe drought than under moderate drought. Under moderate drought stress, the drought/control ratios for RL, RSA, RV, FRL, and TRL were lowest in $\mathrm{V} 1$, and highest in V4. Under severe drought stress, however, the drought/control ratios for RL and FRL of V4 were lowest compared to other varieties. V5 showed 

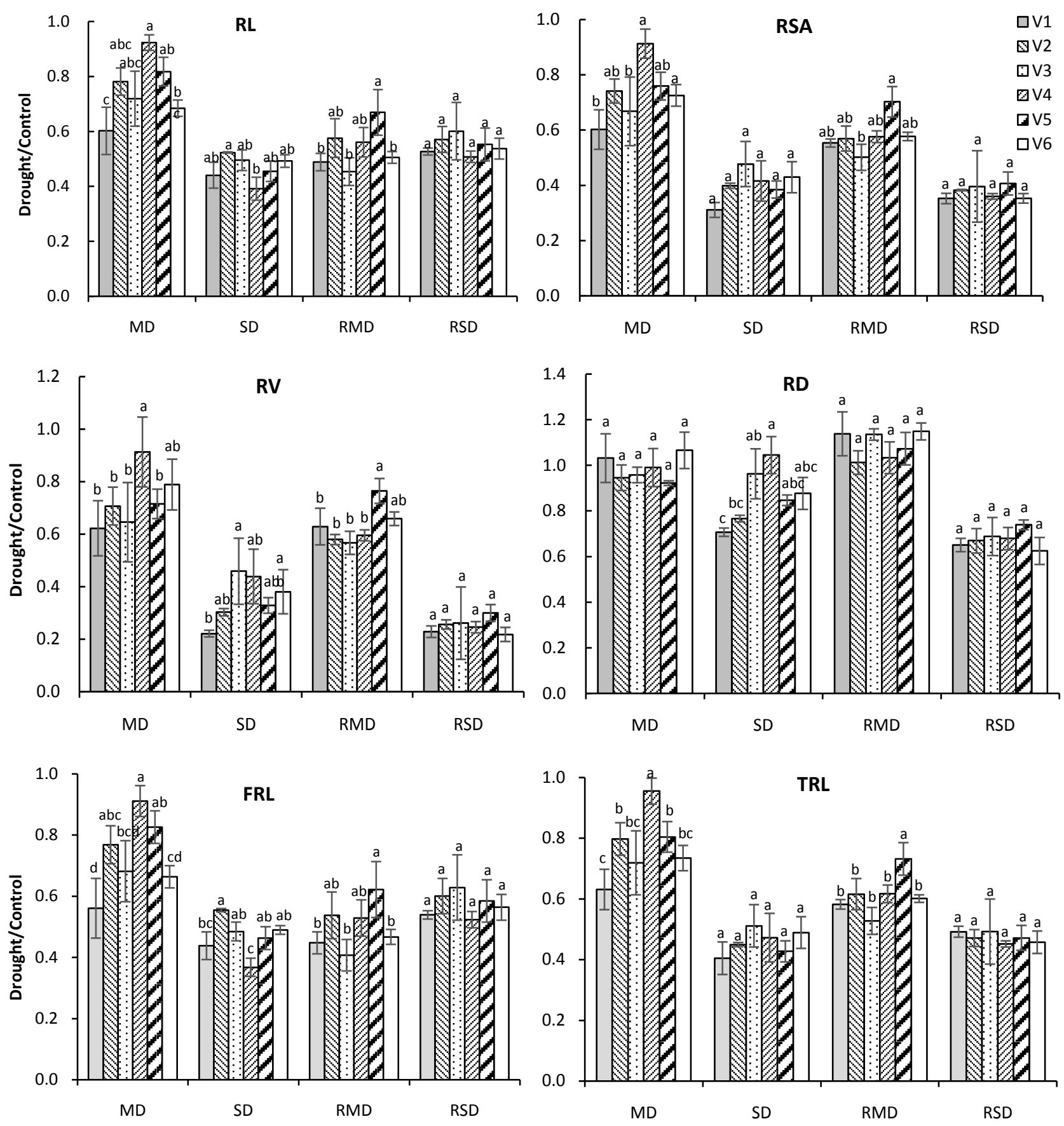

Figure 8. Drought/Control ratios for total root length (RL), root surface area (RSA), root volume (RV), root diameter (RD), fine root length (FRL) and thick root length (TRL) of varieties under different conditions. Foot notes: Same to Figure 2.

the highest recovery/control ratios for RL, RSA, RV, LRL, and TRL during recovery following moderate drought.

\subsection{Stomatal Conductance under Different Conditions}

In plants, stomata control $\mathrm{CO}_{2}$ uptake and water transpiration rates, thereby playing an important role in drought tolerance mechanisms in rice. To explore stomatal responses under drought stress and re-watering conditions, we meas- 
ured stomatal conductance (gs); these data are presented in Figure 9. Under control (well-watered) condition, the highest gs values were exhibited in V1 and the lowest in V5. In all varieties, gs values at 5 days after drought treatment (DAD) and $10 \mathrm{DAD}$ were significantly lower than those under control conditions. At $5 \mathrm{DAD}, \mathrm{V} 5$ showed the highest gs value $\left(106.6 \mathrm{mmol} \cdot \mathrm{m}^{-2} \cdot \mathrm{s}^{-1}\right)$ compared to other varieties, whereas the lowest gs was expressed in $\mathrm{V} 2\left(31.5 \mathrm{mmol} \cdot \mathrm{m}^{-2} \cdot \mathrm{s}^{-1}\right)$. At $10 \mathrm{DAD}, \mathrm{V} 4$ and V6 showed higher gs values than other varieties, and the gs of V3 was lowest. At 3 days of re-watering following moderate drought (3 DRMD) and 3 days of re-watering following severe drought (3 DRSD), the gs values of all varieties were significantly higher than those under drought stress conditions. There were no significant differences in gs among varieties at 3 DRMD. At 3 DRSD, however, the V5 gs value was higher than those of other varieties $\left(251.5 \mathrm{mmol} \cdot \mathrm{m}^{2} \cdot \mathrm{s}^{-1}\right)$.

\section{Discussion}

In this study, we evaluated the effects of different drought stress conditions on the growth characteristics of six rice varieties in terms of dry weight accumulation, root morphology, and stomatal conductance. We also evaluated the recovery ability of the varieties in response to re-watering after drought. Varieties were cultivated in pots of the same size and irrigated with the same amount of water before drought treatment. After drought treatment, soil moisture content decreased significantly in all varieties. However, the pattern of decreasing soil moisture content differed slightly between varieties (Figure 1). These differences

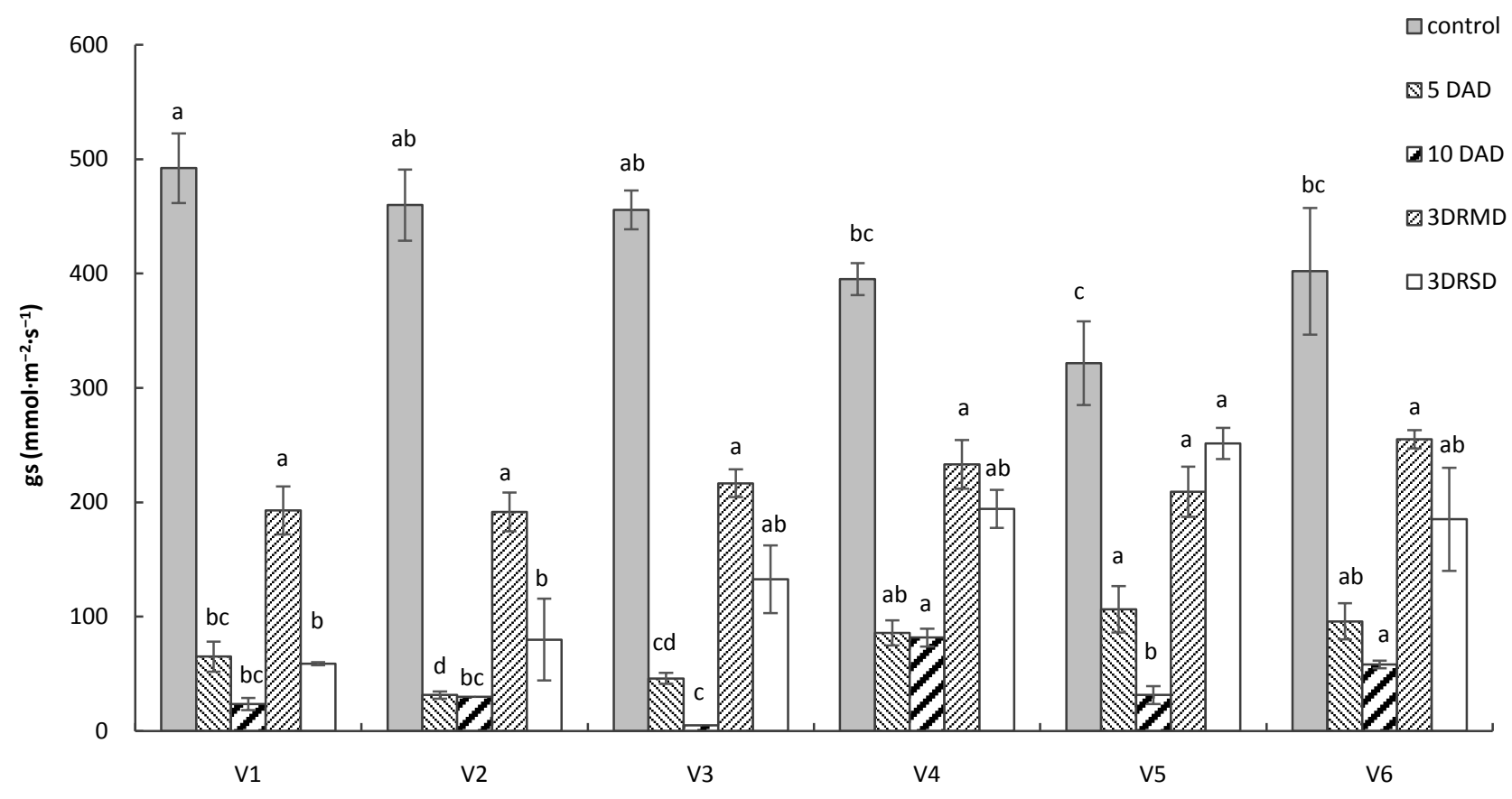

Figure 9. Stomatal conductance (gs) of experimental varieties under different conditions. DAD: Days After Drought Treatment; DRMD: Days after Re-watering from Moderate Drought; DRSD: Days after Re-watering from Severe Drought. Means with the same letter are not significant difference between varieties under the same condition at $\mathrm{p}<0.05$ by Tukeys's HSD Test $(n=3)$. 
can be explained by the diversity in phenotypes among varieties. Tables 1-3 show that V1 (DA8 variety) and V3 (Thierno Bande) generally had higher LDW, SDW, and RDW values than did other varieties under well-watered conditions. These results suggest that these varieties possess larger leaf canopies and root systems.DA8 and Thierno Bande also exhibited higher values for root size characteristics than other varieties under well-watered conditions, particularly during later stages of the study period (Figures 3-7). Consequently, plants of the DA8 and Thierno Bander varieties were capable of greater water absorption, allowing them to retain higher transpiration rates than other varieties. This may explain the more rapid decrease in soil moisture content in DA8 and Thierno Bandepots, compared to those of other varieties.

This study showed that dry weight accumulation in the leaves, stems, and roots of all six varieties was significantly reduced under drought conditions. However, the effects of drought on root and shoot (leaves and stems) parts were not equal. Previous studies have suggested that, under water-limited conditions, the root to shoot ratio increases [24] [25] [26] [27] because root growth is favored over shoot growth [26]. In this experiment, we found that the effects of drought on root and shoot development depended on the severity of drought stresses as well as the variety. Root dry weight was less affected than that of shoots under moderate drought; in contrast, roots were more severely affected than shoots under severe drought (Tables 1-3 and Figure 2). Under drought stress conditions, DA8 generally expressed higher dry weight accumulation than other varieties in the leaves, stems, and roots. In contrast, V2 (Malagkit Pirurutong) showed the lowest LDW accumulation values under moderate drought conditions, with only $1.31 \mathrm{~g} \cdot$ plant $^{-1}$.

Recovery ability following drought stress also plays an important role in rice development [17]. Malabuyoc et al. [20] suggested that recovery ability after drought stress during the vegetative stage was important in determining the production capacity of rice. In our experiment, V5 (Kinandang Patong) showed the highest recovery ability in dry matter accumulation in stems, shoots, and roots after re-watering following moderate drought. Malagkit Pirurutong showed the poorest recovery ability among all varieties in terms of dry weight accumulation (Figure 2).

Root system morphology is an important trait determining drought resistance in rice. To adapt to water-limited conditions, rice roots undergo morphological and anatomical changes [28]; in particular, root growth becomes restricted [29]. The ability to remain and/or develop the root system in response to drought stress reflects phenotypic plasticity. Under drought conditions, total root length, root surface area, and root volume were considerably reduced in all varieties. The results of our experiment are consistent with those of previous studies [29], which have indicated that larger root systems (deeper root length, higher root surface area, and root volume) are important for drought tolerance in rice [30]. Rice root characteristics are significantly correlated with water uptake capacity 
[31]. In this study, the DA8 variety had the highest RL, RSA, RV, and RD values among all varieties. Kinandang Patong showed the highest recovery ability in terms of RL and RSA during the recovery stage following moderate drought.

Under water-limited environments, the initial response of a plant is to prevent the decline in water content in its tissues by balancing the rates of water uptake and water loss, a stress avoidance strategy [32]. Stomatal closure is the immediate and short-term mechanism that plants employ in response to potential water loss [33]. The results of our experiment show that thegs was significantly decreased in all varieties under drought stress conditions. At 5 DAD, Kinandang Patong showed the highest gs value $\left(106.6 \mathrm{mmol} \cdot \mathrm{m}^{-2} \cdot \mathrm{s}^{-1}\right)$, while the lowest value was observed in Malagkit Pirurutong $\left(31.5 \mathrm{mmol} \cdot \mathrm{m}^{-2} \cdot \mathrm{s}^{-1}\right)$. The gs value recovered after re-watering following drought stress. The Kinandang Patonggs value $\left(251.5 \mathrm{mmol} \cdot \mathrm{m}^{2} \cdot \mathrm{s}^{-1}\right)$ was higher than those of all other varieties at 3 DRMD. Thus, Kinandang Patong expressed the highest gs recovery ability after re-watering following drought stress.

\section{Conclusion}

DA8 exhibited the greatest dry matter accumulation and root system development under well-watered, drought stress, and recovery conditions. Kinandang Patong expressed the highest recovery ability during re-watering, in terms of dry weight accumulation, root morphology, and stomatal conductance. Malagkit Pirurutong was observed to be drought-sensitive, having the lowest recovery ability after re-watering. These three varieties will be selected for further study, focusing on the mechanisms of drought tolerance and recovery ability in rice.

\section{Acknowledgements}

This research was supported by a Monbukagakusho Scholarship from the Japanese Ministry of Education, Culture, Sports, Science and Technology (MEXT). The authors thank the Plant Breeding Laboratory, Faculty of Agriculture, Kyushu University, for providing materials for this study. The authors also thank the Agricultural Ecology Laboratory, Faculty of Agriculture, Kyushu University, for providing research facilities.

\section{References}

[1] Bernier, J., Atlin, G., Kumar, A., Serraj, R. and Spaner, D. (2008) Review: Breeding Upland Rice for Drought Resistance. Journal of the Science of Food and Agriculture, 88, 927-939.https://doi.org/10.1002/jsfa.3153

[2] Kamoshita, A., Babu, R.C., Boopathi, N.M. and Fukai, S. (2008) Phenotypic and Genotypic Analysis of Drought-Resistance Traits for Development of Rice Cultivars Adapted to Rainfed Environments. Field Crops Research, 109, 1-23. https://doi.org/10.1016/j.fcr.2008.06.010

[3] Farooq, M., Wahid, A., Lee, D.-J., Ito, O. and Siddique, K.H.M. (2009) Advances in Drought Resistance of Rice. Critical Reviews in Plant Sciences, 28, 199-217. https://doi.org/10.1080/07352680902952173 
[4] Blum, A. (2011) Plant Breeding for Water-Limited Environments. Springer, New York. https://doi.org/10.1007/978-1-4419-7491-4

[5] Plaut, Z. (2003) Plant Exposure to Water Stress during Specific Growth Stages. In: Encyclopedia of Water Science, Marcel Dekker Inc., New York, 673-675.

[6] Cutler, J.M., Steponkus, P.L., Wach, M.J. and Shahan, K.W. (1980) Dynamic Aspects and Enhancement of Leaf Elongation in Rice. Plant Physiology, 66, 147-152. https://doi.org/10.1104/pp.66.1.147

[7] Hsiao, T.C., O’Toole, J.C., Yambao, E.B. and Turner, N.C. (1984) Influence of Osmotic Adjustment on Leaf Rolling and Tissue Death in Rice. Plant Physiology, 75, 328-341. https://doi.org/10.1104/pp.75.2.338

[8] Turner, N.C., O’Toole, J.C., Cruz, R.T., Namuco, O.S. and Ahmad, S. (1986) Response of Seven Diverse Rice Cultivars to Water Deficits. I. Stress Development, Canopy Temperature, Leaf Rolling and Growth. Field Crops Research, 13, 257-271. https://doi.org/10.1016/0378-4290(86)90027-4

[9] O’Toole, J.C., Hsiao, T.C. and Namuco, O.S. (1984) Panicle Water Relations during Water Stress. Plant Science Letters, 33, 137-143. https://doi.org/10.1016/0304-4211(84)90003-8

[10] Farooq, M., Hussain, M., Wahid, A. and Siddique, K.H.M. (2012) Plant Responses to Drought Stress. Springer-Verlag, Berlin Heidelberg.

[11] Yoshida, S. and Hasegawa, S. (1982) Drought Resistance in Crops with Emphasis on Rice. International Rice Research Institute. Manila, Philippines.

[12] O’Toole, J.C. and Bland, W.L. (1987) Genotypic Variation in Crop Plant Root System. Advances in Agronomy, 41, 91-145. https://doi.org/10.1016/S0065-2113(08)60803-2

[13] Hodge, A. (2004) The Plastic Plant: Root Responses to Heterogeneous Supplies of Nutrients. New Phytologist, 162, 9-24. https://doi.org/10.1111/j.1469-8137.2004.01015.x

[14] Kano, M., Inukai, Y., Kitano, H. and Yamauchi, A. (2011) Root Plasticity as the Key Root Strait for Adaptation to Various Intensities of Drought Stress in Rice. Plant and Soil, 342, 117-128. https://doi.org/10.1007/s11104-010-0675-9

[15] O’Toole, J.C. and Chang, T.T. (1979) Drought and Rice Improvement in Perspective. IRRI Research Paper Series, No. 14, International Rice Research Institute.

[16] Boyer, J.S. (1996) Advances in Drought Tolerance in Plants. Advances in Agronomy, 56, 187-219. https://doi.org/10.1016/S0065-2113(08)60182-0

[17] Chang, T.T., Loresto, G.C. and Tagumpay, O. (1974) Screening Rice Germplasm for Drought Resistance. SABRAO, 6, 9-16.

[18] De Datta, S.K., Chang, T.T. and Yoshida, S. (1975) Drought Tolerance in Upland Rice. In: Major Research in Upland Rice, International Rice Research Institute, Los Banos, 101-116.

[19] Sarkar, J.P. and De Datta, S.K. (1975) Drought Tolerance in Rice: Screening Technique and Selection Criteria. IRRI Saturday Seminar, Los Banos, 18 August 1975.

[20] Malabuyoc, J.A., Aragon, E.L. and De Datta, S.K. (1985) Recovery from Drought-Induced Desiccation at the Vegetative Growth Stage in Direct-Seeded Rainfed Rice. Field Crops Research, 10, 105-112. https://doi.org/10.1016/0378-4290(85)90018-8

[21] Dien, D.C., Mochizuki, T. and Yamakawa, T. (2017) Morphology and Dry Matter Accumulation in Rice (Oryzasativa L.) Seedlings under Drought Conditions. Journal of Faculty of Agriculture, Kyushu University, 72. 
[22] Yamauchi, A., Pardales Jr, J.R. and Kono, Y. (1996) Root System Structure and Its Relation to Stress Tolerance. In: Dynamics of Roots and Nitrogen in Cropping Systems of the Semi-Arid Tropics, Japan International Research Center for Agricultural Sciences, Tokyo, 211-233.

[23] Tran, T.T., Kano-Nakata, M., Takeda, M., Menge, D., Mitsuya, S., Inukai, Y. and Yamauchi, A. (2014) Nitrogen Application Enhanced the Expression of Developmental Plasticity of Root Systems Triggered by Mild Drought Stress in Rice. Plant and Soil, 378, 139-152. https://doi.org/10.1007/s11104-013-2013-5

[24] Banda, K. and Ookubo, T. (1981) Relationship between Root Distribution of Upland Crops and Their Yield. 3. Influence of Soil Moisture Levels on Root Distribution and Root Dry Matter of Upland-Cultured Paddy Rice, and Upland Rice. Japanese Journal of Crop Science, 50, 1-7. (In Japanese) https://doi.org/10.1626/jcs.50.1

[25] Kondo, M., Maddala, V.R. and Aragones, D.V. (2000) Characteristics of Root Growth and Water Uptake from Soil in Upland Rice and Maize under Water Stress. Soil Science and Plant Nutrition, 46, 721-732. https://doi.org/10.1080/00380768.2000.10409137

[26] Kato, Y., Abe, J., Kamoshita, A. and Yamagishi, J. (2006) Genotypic Variation in Root Growth Angle in Rice (Oryza sativa L.) and Its Association with Deep Root Development in Upland Fields with Different Water Regimes. Plant and Soil, 287, 117-129. https://doi.org/10.1007/s11104-006-9008-4

[27] Xu, W., Cui, K., Xu, A., Nie, L., Huang, J. and Peng, S. (2015) Drought Stress Condition Increases Root to Shoot Ratio via Alteration of Carbohydrate Partitioning and Enzymatic Activity in Rice Seedlings. Acta Physiologiae Plantarum, 37, 2. https://doi.org/10.1007/s11738-014-1760-0

[28] Kato, Y. and Katsura, K. (2014) Rice Adaptation to Aerobic Soils: Physiological Considerations and Implications for Agronomy. Plant Production Science, 17, 1-12. https://doi.org/10.1626/pps.17.1

[29] Kato, Y. and Okami, M. (2010) Root Growth Dynamics and Stomatal Behavior of Rice (Oryza sativa L.) Grown under Aerobic and Flooded Conditions.

[30] Uga, Y., Sugimoto, K., Ogawa, S., Rane, J., Ishitani, M., Hara, N., Kitomi, Y., Inukai, Y., Ono, K., Kanno, N., et al. (2013) Control of Root System Architecture by Deeper Rooting 1 Increases Rice Yield under Drought Conditions. Nature Genetics, 45, 1097-1102. https://doi.org/10.1038/ng.2725

[31] Ingram, K.T., Bueno, F.D, Namuco, O.S., Yambao, E.B. and Beyrouty, C.A. (1994) Rice Root Traits for Drought Resistance and Their Genetic Variation. In: Kirk, G.J.D., Ed., Rice Roots. Nutrient and Water Use, IRRI, Phillipines, 67-77.

[32] Verslues, P.E., Agarwal, M., Katiyar-Agarwal, S., Zhu, J. and Zhu, J.-K. (2006) Methods and Concepts in Quantifying Resistance to Drought, Salt and Freezing, Abiotic Stresses That Affect Plant Water Status. The Plant Journal, 45, 523-539. https://doi.org/10.1111/j.1365-313X.2005.02593.x

[33] Oliver, M.J., Cushman, J.C. and Koster, K.L. (2010) Dehydration Tolerance in Plants. In: Plant Stress Tolerance: Methods and Protocols, 3-24. https://doi.org/10.1007/978-1-60761-702-0_1 